\title{
A novel method to detect translation of membrane proteins following microvesicle intercellular transfer of nucleic acids
}

Running Title: Novel method to detecting nucleic acid translation.

Jamie F. Lu ${ }^{1 \#}$, Deep Pokharel ${ }^{1 \#}$, Matthew P. Padula², Mary Bebawy ${ }^{1 *}$

\# These authors contributed equally to this work.

${ }^{1}$ Discipline of Pharmacy, The Graduate School of Health, University of Technology Sydney, NSW, 2007, Australia.

${ }^{2}$ Proteomics Core Facility, University of Technology Sydney, NSW 2007 Australia

* Corresponding Author

Associate Professor Mary Bebawy,

Discipline of Pharmacy,

The Graduate School of Health,

University of Technology Sydney,

PO Box 123, Broadway, NSW, 2007, Australia.

Tel: +61295148305

Fax: +61295148300

Email: mary.bebawy@uts.edu.au

Final Character Count: 35,718

Keywords: Microvesicles, Multidrug Resistance, mRNA, P-glycoprotein, nucleic acids, 
Abbreviations: Flow cytometry, FCM; Cyclosporin A, csA; Mean Fluorescence Intensity, MFI; Microvesicles, MVs; Multidrug Resistance, MDR; P-glycoprotein, P-gp; Rabbit Reticulocyte Translation assay, RRTA.

\section{SUMMARY}

Microvesicles (MVs) serve as vectors of nucleic-acid dissemination and are important mediators of intercellular communication. However, the functionality of packaged nucleic acids on recipient cells following transfer of MV-cargo has not been clearly elucidated. This limitation is attributed to a lack of methodology available in assessing protein translation following homotypic intercellular transfer of nucleic-acids. Using surface peptide shaving we have demonstrated that MVs derived from human leukaemic cells transfer functional Pglycoprotein transcripts, conferring drug-efflux capacity to recipient cells. We demonstrate expression of newly synthesized protein using Western blot. Furthermore, we show functionality of translated P-gp protein in recipient cells using Calcein-AM dye exclusion assays on flow cytometry. Newly synthesized $170 \mathrm{kDa}$ P-gp was detected in recipient cells after co-culture with shaven MVs and these proteins were functional, conferring drug-efflux. This is the first demonstration of functionality of transferred nucleic-acids between human homotypic cells as well as the translation of the cancer multidrug-resistance protein in recipient cells following intercellular transfer of its transcript. This study supports the significant role of MV's in the transfer of deleterious traits in cancer populations and 
describes a new paradigm in mechanisms governing the acquisition of traits in cancer cell populations.

\section{INTRODUCTION}

MVs (Microvesicles) are shed from a diverse range of eukaryotic and prokaryotic cells either spontaneously or following cellular activation or stress (1). They selectively transfer the phenotypic and genotypic characteristics of their parental cell by packaging proteins and nucleic acids upon vesiculation (1-4). MV's have been shown to participate in a variety of processes involving the development of immune tolerance, immune activation, phenotype modification, cell-cell signalling, drug-sequestration and reprogramming of cell function (1, 3-6). Numerous studies have demonstrated the presence of RNA, mRNA and miRNA in MVs $(1,4,6-8)$, with some nucleic acid species being either selectively packaged or completely absent during the MV vesiculation and transfer processes $(1,6)$. Consequently, MVs have emerged as important vehicles for nucleic acid based communication between cells.

In assessing functionality of the transferred nucleic acid cargo, previous studies have used interspecies methodologies to establish nucleic acid functionality following intercellular transfer by MV's (8). However, this approach is not physiologically relevant due to interspecies differences, which may impact on protein translation of the foreign transcript in recipient cells. Furthermore, there have been no technical means to distinguish between the translation of conferred transcript and the transfer of endogenous protein contained within the MV cargo, hence confounding results. Other attempts to detect protein translation from MV-RNA have utilised labelled probes such as luciferase reporter 
genes (7). Once again this does not reflect the native nucleic acid cargo of MV's.

Consequently, the functionality of transferred native MV-RNA between homotypic cells has remained unestablished.

Herein, we demonstrate for the first time, the translation of native human MV-RNA in recipient human cells following intercellular transfer by MV's. This study establishes the functionality of human MV-nucleic acids encoding transmembrane proteins by employing MV surface peptide shaving. We anticipate this methodology will be used to assess the expression of membrane bound proteins in the context of MV-transfer. This study demonstrates for the first time that MV's confer phenotypic changes in recipient cells following the transfer of functional nucleic acids in addition to the transfer of functional proteins and reinforces the significance of MV's in the acquisition cellular traits.

\section{MATERIALS AND METHODS}

\section{Cell Lines}

The drug sensitive human acute lymphoblastic leukaemia cell line CCRF-CEM (designated CEM for simplicity) and its MDR derivative, VLB 100 was used in this study. VLB 100 cells hyper-express functional cell surface P-gp relative to the parental drug sensitive CCRFCEM cells. The CEM and VLB 100 cell lines have been validated earlier by us as an appropriate model for study of P-gp mediated MDR in vitro $(3,9,10)$. All cell lines were cultured in RPMI1640 media (Sigma-Aldrich, NSW, Australia), supplemented with 10\% heat-inactivated foetal bovine serum (Invitrogen, Life Technologies, Victoria, Australia) and maintained at $37^{\circ} \mathrm{C}$ and $5 \% \mathrm{CO} 2$. All cells lines were tested for mycoplasma contamination routinely. 


\section{MV isolation}

MVs were isolated from $5 \times 10^{9}-7 \times 10^{9}$ cells by differential centrifugation, as described previously $(3,4,11)$. The integrity and purity of the isolated MV fraction have been previously extensively validated by us $(3,4)$. This amount yields approximately $2 \mathrm{mg}$ of total MV protein in $100 \mu \mathrm{L}$ final volume. Briefly, cell supernatant was collected and centrifuged at $500 \times g$ for 5 min to pellet the cell population or debris. The supernatant was further centrifuged at $15,000 \times g$ for $1 \mathrm{~h}$ at $15^{\circ} \mathrm{C}$ and the pellet was resuspended in serum free RPMI-1640. The MV fraction was further centrifuged at $2000 \times g$ for $1 \mathrm{~min}$ to remove remaining debris. To concentrate the MV fraction, the supernatant was further centrifuged at $18,000 \times g$ for $30 \mathrm{~min}$ and resuspended in serum free RPMI-1640. MV total protein content was quantified using Qubit ${ }^{\circledR}$ 2.0 Fluorometer protein assay (Invitrogen, Life Technologies) as per the manufacturer's instructions.

\section{Flow Cytometric analysis}

To confirm the presence of nucleic acids in MVs, flow cytometric analysis (LSRII, BD Biosciences, CA, USA) was used following acridine orange (AO) (Sigma-aldrich) staining. Cytograms were acquired using BD FACSDiva software (BD Biosciences) and analyzed using BD Cell-Quest Pro (BDBiosciences). Approximately $50 \mu \mathrm{g}$ of MVs were treated with RNAse A (Invitrogen, Life technologies) and resuspended in $200 \mu \mathrm{L}$ of $\mathrm{RPMI}^{-}$and incubated with AO to a final concentration of $20 \mu \mathrm{mol} / \mathrm{L}$. Unstained MVs were used as the control.

MV integrity was assessed using the calcein-AM (Invitrogen, Life technologies drug exclusion assay. Calcein-AM is a non-fluorescent membrane permeable drug. Upon entering MVs, calcein-AM is cleaved by endogenous esterases to its fluorescent non-membrane permeable form, calcein (4). Approximately $50 \mu \mathrm{g}$ of MVs were stained with $0.1 \mu \mathrm{M}$ calcein- 
AM for $1 \mathrm{~h}$ at $37^{\circ} \mathrm{C}$ and $5 \% \mathrm{CO}_{2} . \mathrm{MVs}$ were washed twice with PBS to remove unincorporated calcein-AM and resuspended in $200 \mu \mathrm{L}$ of PBS for flow cytometric analysis.

For cell-MV binding studies, MVs are stained with the cell membrane dye PKH26 (sigma-aldrich) for 1 minute according to the manufacturer's instructions, immediately followed by two washes with PBS at $18,000 \times \mathrm{g}$. MVs are then immediately analysed on the flow cytometer or used in co-culture experiments with recipient CEM cells.

In assessing cell binding of MV's to recipient cells, 1 × $10^{5} \mathrm{CEM}$ cells were co-cultured in a 96 well plate at $37^{\circ} \mathrm{C}, 5 \% \mathrm{CO}_{2}$ for $4 \mathrm{~h}$ with $180 \mu \mathrm{g}$ of $\mathrm{MVs}$ preloaded and labelled with calcein-AM, AO and PKH26 MVs respectively. The $4 \mathrm{~h}$ time point has been previously validated by us to be sufficient time for the transfer of functional protein and nucleic material from MV's to recipient cells $(3,4,6,12)$. Cells are subsequently washed thrice with PBS at $500 \times \mathrm{g}$ for $5 \mathrm{~min}$ at room temperature to remove unbound MVs. Cells were resuspended in $200 \mu \mathrm{L}$ of PBS before analysis on the flow cytometer.

\section{In vitro rabbit reticulocyte translation}

The in vitro rabbit reticulocyte translation kit (Promega, NSW, Australia) was used according to the manufacturers instruction with the exception that a total of $400 \mu \mathrm{g} / \mathrm{mL}$ final concentration of total MV RNA was used to obtain efficient translation of P-gp/ABCB1 from MV's. A rabbit reticulocyte lysate sample without RNA was used as the control. Samples were immediately stored at $-20^{\circ} \mathrm{C}$ until required.

Total RNA was isolated from MVs and cells using the RNeasy mini kit with genomic DNA eliminator (Qiagen, NSW, Australia). $300 \mu \mathrm{g}-1 \mathrm{mg}$ MVs were pelleted at $18,000 \times \mathrm{g}$ and disrupted and homogenized using 350-600 $\mu \mathrm{L}$ of buffer RLT plus (Qiagen, NSW, 
Australia). Purified total RNA was isolated from the homogenate according to the manufacturer's protocol. The RNA isolate was resuspended in $30 \mu \mathrm{L}$ of RNAse free $\mathrm{H}_{2} \mathrm{O}$ and quantified using the Nanodrop 1000 spectrophotometer (Nanodrop technologies, DE, USA). Purified total RNA was stored at $-80^{\circ} \mathrm{C}$ until required.

\section{SDS-PAGE and Trypsin in-gel digestion}

$4 \mu \mathrm{L}$ of rabbit lysate, as prepared above, was mixed with $2 x$ SDS sample buffer containing Tris- $\mathrm{HCl}$, glycerol, SDS, bromophenol blue and water $(\mathrm{pH} 8.8)$ at a ratio of 2:1 (protein : SDS buffer). The sample was sonicated in a waterbath for 5 min followed by centrifugation for $5 \mathrm{~min}$ at 16,500 $\mathrm{g} g$ at ambient temperature. Proteins were separated using 4-10\% SDS-PAGE at a voltage of $150 \mathrm{~V}$ in MES SDS running buffer (Invitrogen, Life Technologies). The gel was fixed with 40\% Methanol / 10\% Acetic acid for 30 min with gentle shaking before staining with Coomassie blue overnight. In-gel trypsin digestion was performed as previously described by us (2). Briefly, the gel was sectioned into 12 pieces, according to the MW markers and the sections diced into $1 \times 1 \mathrm{~mm}$ pieces which were destained by adding $50 \%$ acetonitrile (ACN)/50 mM NH4HCO3 and incubated for $10 \mathrm{~min}$ at ambient temperature. The process was repeated until the Coomassie stain disappeared. $100 \% \mathrm{ACN}$ was added to dehydrate the gel pieces before rehydration with $12.5 \mathrm{ng} / \mu \mathrm{L}$ of trypsin solution (Trypsin Gold-MS grade, Promega) and overnight incubation at $37^{\circ} \mathrm{C}$. After incubation, the supernatant was collected after sonication in a water-bath for $10 \mathrm{~min}$, followed by another sonication following the addition of $30 \mu \mathrm{l}$ of $50 \% \mathrm{ACN} / 2 \%$ formic acid. The solution was added to the previously collected peptides and the volume reduced to 15 $\mu \mathrm{L}$ by rotary evaporation. The peptide solution was centrifuged at $14,000 \times \mathrm{g}$ for $10 \mathrm{~min}$ to 
remove any insoluble material prior to LC/MS/MS analysis. LC/MS/MS experiments and analysis was performed as described previously (2).

\section{MV surface shaving}

To determine whether $A B C B 1$ transcript packaged in MVs could be transferred and translated in human recipient cells, we used surface shaving methodology to eliminate endogenously packaged transmembrane proteins on the MV membrane using proteinase $\mathrm{K}$ digestion prior to co-culture with recipient cells. Our approach allows for the detection of newly synthesized transmembrane protein in recipient cells and eliminates endogenous protein present in MV's, which would confound the results. Briefly, the MV pellet was resuspended in PBS, pH 7.8 at room temperature. Samples, including proteinase $\mathrm{K}$ were prewarmed for $15 \mathrm{~min}$ in $37^{\circ} \mathrm{C} .20-200 \mathrm{ng} / \mathrm{mL}$ of proteinase $\mathrm{K}$ was added to the MV sample and incubated for $5 \mathrm{~min}$ at $37^{\circ} \mathrm{C}$. To stop the reaction, protease cocktail (1\%) (Sigma-Aldrich) was immediately added to the sample. MVs were washed twice with ice cold PBS for $18,000 \mathrm{xg}$ at $4^{\circ} \mathrm{C}$ and the pellet resuspended in serum free RPM- 1640 .

\section{Translation of MV derived nucleic acid in CEM cells}

Shaved and non-shaved VLB $100 \mathrm{MVs}(180 \mu \mathrm{g})$ were co-cultured with $1 \times 10^{5} \mathrm{CEM}$ cells to a final volume of $200 \mu \mathrm{L}$ in complete RPMI medium supplemented with $10 \%$ FCS and maintained at $37^{\circ} \mathrm{C}, 5 \% \mathrm{CO}_{2}$ in 96 well plates. At specific time intervals, cells were washed twice with pre-warmed $\left(37^{\circ} \mathrm{C}\right)$ PBS to remove unbound MVs before Western blot analysis. CEM cells alone were used as the control. The newly translated P-gp was detected using the anti-P-gp antibody (clone F4, Sigma-Aldrich). 


\section{SDS-PAGE and Western Blotting}

The isolated MV pellet and cells were lysed in CelLytic $\mathrm{M}^{\mathrm{TM}}$ Cell Lysis reagent (C2978; Sigma-Aldrich) in the presence of $1 \%(v / v)$ protease inhibitor cocktail (P8340, Sigma-Aldrich) on ice for $30 \mathrm{~min}$. The lysates were centrifuged at $10,000 \times \mathrm{g}$ for $10 \mathrm{~min}$ at $4^{\circ} \mathrm{C}$ to pellet the debris. Total protein lysate was quantified using Qubit ${ }^{\circledR} 2.0$ Fluorometer (Invitrogen, Life Technologies) as per the manufacturer's instructions.

30-60 $\mu \mathrm{g}$ of total protein was separated by electrophoresis using a 4-12\% NUPAGE Bis-Tris gel (Invitrogen, Life Technologies) at a constant voltage of $150 \mathrm{~V}$ for $60 \mathrm{~min}$ and transferred onto a PVDF membrane at $30 \mathrm{~V}$ for $90 \mathrm{~min}$. For detection of P-gp and $\beta$-actin control, 1:1000 dilution of anti-P-gp mAb (Clone C219, Amersham Biosciences, Piscataway, NJ), 1:5000 dilution of anti-P-gp (Clone F4, Sigma-aldrich, NSW, Australia) and 1:10,000 dilution of anti- $\beta$-actin antibody (Clone AC-74, Sigma-Aldrich) was used. Incubation of antibodies was overnight at $4^{\circ} \mathrm{C}$ after blocking for $1 \mathrm{~h}$ with $5 \%$ skim milk in TBS and $0.05 \%$ Tween 20 (TBST). After washing 3 times in TBST, the membranes were incubated for $1 \mathrm{~h}$ with anti-Mouse-HRP secondary antibody (Promega, NSW, Australia) at 1:10,000 dilution. Novex ${ }^{\circledast}$ Sharp Pre-Stained standard (LC5800, Life technologies, Australia) was used as a molecular weight marker. Protein expression was visualised using an ECL (enhanced chemoluminescence) system (Roche Applied Science, NSW, Australia). The membranes were imaged using the luminescent image analyser LAS-3000 (Fujifilms, Brookvale, NSW, Australia).

\section{Calcein-AM dye exclusion assay}


Calcein-AM dye exclusion has been extensively used to measure P-gp and MRP1

functionality $(4,11,13)$. Briefly MVs isolated from VLB $\operatorname{Lion}_{100}$ cells were co-cultured with $1 \times 10^{5}$ CEM cells and maintained at $37^{\circ} \mathrm{C}$ and $5 \% \mathrm{CO}_{2}$ in 96 -well plates. After 4 hours, the recipient cells were washed twice with complete culture medium to remove unbound MVs and treated with $0.1 \mu \mathrm{M}$ of Calcein-AM for $1 \mathrm{~h}$ in the presence and absence of a $1 \mathrm{~h}$ preincubation with $10 \mu \mathrm{M}$ cyclosporin $\mathrm{A}(\mathrm{CsA})(11)$ at $37^{\circ} \mathrm{C}$ and $5 \% \mathrm{CO}_{2}$. The cells were subsequently washed three times with PBS and re-suspended in $200 \mu \mathrm{L}$ PBS for flow cytometric analysis.

\section{Statistical Analysis}

Means between groups were compared using an unpaired two-tailed students t-test. P-values less than $0.05(P<0.05)$ were accepted as statistically significant. All statistical analyses were performed using GraphPad Prism version 5.0 for Windows Software (Graphpad Software, CA, USA).

\section{RESULTS}

\section{MVs package functional $A B C B 1$ transcript}

We previously showed the packaging and transfer of mRNA encoding the ATP Binding Cassette superfamily of drug transporters $(A B C B 1$ and $A B C C 1)$ by $M V$ s into recipient cells $(4,6,11)$. Herein, we sought to establish the functionality of these transferred transcripts in recipient cells following MV transfer. The functionality of MV packaged mRNA was first confirmed in vitro using a rabbit reticulocyte translation assay (RRTA). The expression of the cancer multidrug resistant protein, P-gp (coded by gene $A B C B 1$ ) was used 
as the reporter protein for the mRNA translation studies in the first instance. Using RRTA and the anti-P-gp clone F4 antibody, we observed a 170 kDa band (Figure 1) after the addition of total RNA purified from VLB ${ }_{100} M V s$ (final $400 \mu \mathrm{g} / \mathrm{mL}$ ) supporting in vitro translation of RNA into protein. We subsequently sought to examine the full repertoire of proteins translated using the RRTA system using shotgun proteomics (Table 1). We identified more than 200 proteins (Supplementary data Table 1) in our RRTA, of which 5 were unique when compared to RRTA in absence of RNA (Table 1).

\section{MV-RNA is translated in recipient cells.}

To assess functionality of the transcripts in recipient cells following MV transfer of cargo, we first needed to eliminate detection of the endogenous transmembrane P-gp on the surface of MVs prior to co-culture with recipient cells. Doing so would ensure that any protein detected in recipient cells was a function of translation of cargo transcript rather than the transfer of functional P-gp contained within the MV's. In approaching this, we developed a novel approach using the non-specific protease, proteinase $\mathrm{K}$, to cleave overhanging transmembrane segments of P-gp on the surface of MVs. Following which, we co-cultured the surface 'shaved' MVs with CEM cells to detect translation of full length protein from donor transcripts in the recipient cells.

\section{i. MV integrity is maintained following surface shaving}

MVs were isolated and validated as previously described by us $(1,3,4,6,11)$. Using 1.1 $\mu \mathrm{M}$ latex size beads (Sigma-Aldrich, NSW, Australia), events greater than $1.1 \mu \mathrm{M}$ in size were excluded from flow cytometry (FCM) analysis by size gating (Figure $2 A$ ). VLB $100 M V s$ 
were identified as Annexin-V450 positive events and represented $61.95 \%$ of the gated population $(3,4,6)$. This result is consistent with our previous findings, which demonstrate spontaneous shedding of MVs from the P-gp overexpressing cell line, $\operatorname{VLB}_{100}(3,4,6)$.

To confirm the membrane integrity of MV's following surface shaving, we assessed the retention of intravesicular acridine orange $(A O)$ and calcein-AM stains in MVs by FCM following dye loading as previously described by us (Figure 2C, 2D). Calcein-AM is a membrane permeable non-fluorescent drug. Upon entering MVs, calcein-AM is cleaved by endogenous esterases to its fluorescent non-membrane permeable form, calcein, which remains trapped in the intravesicular space (4). We observed a small but significant $1.36 \pm$ 0.07 fold, $(P<0.05)$ increase in fluorescent calcein accumulation in MVs following surface shaving using $50 \mathrm{ng} / \mathrm{mL}$ Proteinase K. Despite this increase in calcein-AM permeability, we confirm the RNA content of shaved vesicles was not compromised as assessed by AO staining (Figure 3). We observed no significant difference in the AO fluorescence intensities when we compared shaved and non-shaved MVs, consistent with the maintenance of MV integrity and no leakage of the intra-vesicular nucleic acid material (Figure 3).

\section{ii. Surface peptide shaving does not compromise $M V$ binding to recipient cells}

In assessing whether surface shaving impacted on cell binding of MV's to recipient cells we co-cultured CEM cells with MVs preloaded and labelled with calcein-AM, AO and PKH26 (Figure 3). Whole cells were washed and analysed by FCM to determine the uptake of stained MVs following co-culture. Enhanced fluorescence was detected in recipient CEM cells following co-culture with shaved and non-shaved MVs relative to the unstained control. We observed no significant difference in $\mathrm{MFI}$ in recipient CEM cells after co-culture 
with either shaved or non-shaved MVs. (Figure 3). This suggests that the binding of MVs shed from $\mathrm{VLB}_{100}$ cells does not require exposed surface proteins, with the process relying on the physical interaction between the two membranes (Figure 3). This is contrary to some previous reports that show that recognition between MVs and their target cells involves the specific interaction between proteins (eg. ICAM-1, CD44, LFA-1, H-2Kb and CD81) at the surface of both cells and MV (14-17). Here, the surface shaving of MVs with proteinase K, did not significantly affect binding of MV's to recipient CEM cells. One possible reason for non-selectivity is the cell type in question, with the immunological origin of VLB 100 MV's and their reliance to interact with numerous cell types in the context of their immunological role

\section{iii. The molecular weight of P-gp changes following surface shaving}

Following proteinase $\mathrm{K}$ surface shaving we detected a change in the molecular weight of endogenous P-gp contained within the MV's. Specifically we observed a reduction of the proteins molecular weight from $170 \mathrm{kDa}$ to the detection of multiple fragments around the $42 \mathrm{KDa}$ size range (Figure 4). We observed a concentration dependent effect on the proteolytic digestion of P-gp. Treatment with $20 \mathrm{ng} / \mathrm{mL}$ of proteinase $\mathrm{K}$ for $5 \mathrm{~min}$, resulted in a smearing around the $170 \mathrm{kDa}$ region, consistent with incomplete shaving of surface peptides. Upon treatment with $50 \mathrm{ng} / \mathrm{mL}$ or more of proteinase $\mathrm{K}$, we observed a complete loss of the $170 \mathrm{kDa}$ band consistent with the proteolytic digestion of the protein (Figure 3). 


\section{iv. Newly synthesized full length P-gp is detectable in recipient cells following MV co-culture}

In detecting functionality of the transferred nucleic acid transcript in recipient cells, shaved VLB ${ }_{100} M V s$ were co-cultured with recipient CEM cells, the latter inherently devoid of P-gp expression (Figure 5). Considering that human P-gp has a turnover of approximately $18.3 \mathrm{~h}(18)$, we co-cultured for periods of $19 \mathrm{~h}$ and $24 \mathrm{~h}$. We observed a $170 \mathrm{kDa}$ P-gp band in recipient CEM cells by Western blot analysis at both time points (Figure 5). The presence of the P-gp band is consistent with the transfer and translation of the $A B C B 1$ transcript in recipient cells following MV co-culture.

\section{Newly synthesised P-gp is functional in the recipient cells.}

To investigate the drug efflux functionality of the newly translated P-gp in the recipient cells, the calcein-AM dye exclusion assay was used following a $4 \mathrm{~h}$ and $24 \mathrm{~h}$ coculture with shaven MV's (Figure 6). The exclusion of calcein-AM in P-gp expressing cells is dependent on the functionality of the protein and is commonly used in the assessment of Pgp mediated $\operatorname{MDR}(4,11,19)$. We previously reported the transfer and functionality of P-gp in recipient CEM cells following a $4 \mathrm{~h}$ co-culture period and attributed this to the transfer of functional P-gp contained within the MV's (3). Following $4 \mathrm{~h}$ co-culture with shaven $\mathrm{VLB}_{100} \mathrm{MVs}$ we observed no significant difference in calcein accumulation (Figure 6), consistent with the loss of functionality following surface shaving. Upon $24 \mathrm{~h}$ co-culture with shaven MVs, we observed a significant $1.311( \pm 0.072)$ fold decrease in calcein accumulation 
in recipient cells (Figure 6), consistent with the presence of translated and functional protein at this time (Figure 5).

To further validate the functionality of the newly translated protein in recipient cells, the effects of the P-gp inhibitor Cyclosporin A (CsA) were examined. In the presence of 10 $\mu \mathrm{M}$ CsA, we observed a significant $1.37( \pm 0.114)$ fold reversal of calcein accumulation relative to control CEM cells alone (Figure 6), consistent with the pharmacological inhibition of P-gp mediated transport of calcein in the recipient cells. Similarly, we observed a significant $2.37( \pm 0.68)$ fold reversal in CsA treated control VLB ${ }_{100}$ cells compared to VLB 100 cells alone, demonstrating the inhibition of P-gp mediated drug efflux in our controls. These results evidence the presence of functional P-gp following MV transfer of functional nucleic acid in recipient cells.

\section{DISCUSSION}

Currently there is no methodology that allows for the detection of newly synthesized proteins in their native form as a result of homotypic nucleic acid transfer by MVs. Previous studies that utilize cross-species co-culture models (8) or reporter gene methodologies to demonstrate mRNA functionality (7) do not reflective of the native endogenous state. We report for the first time the translation of native, unlabelled human MV-RNA in human recipient cells following intercellular transfer by MV's.

We confirm the packaging of functional transcripts in microvesicles using a RRTA. The observation of a $170 \mathrm{kDa}$ P-gp band on Western blot after addition of VLB $100 \mathrm{MV}$ total RNA into a RRTA system establish that MV's carry intact functional transcripts (Figure 1). It 
should be noted however, that post-translational glycosylation events may vary between batches (20). We further identify additional proteins translated from VLB ${ }_{100} M V$ RNA using tandem mass spectrometry (Table 1). The reason for the large overlap between sample and background, we believe is due to the cross species conservation of proteins (21). We identify 5 unique proteins from the VLB ${ }_{100} \mathrm{MV}$ translation lysate including P-gp, 60S ribosomal protein L26, Isoform 2 of 4F2 cell-surface antigen heavy chain, proteasome subunit beta type 6 and sodium/potassium-transporting ATPase subunit alpha-4. These proteins are reported to play a significant role in human cancer tumorigenesis and multidrug resistance (Table 1).

Using surface shaving methodology we demonstrate for the first time functionality of MV nucleic acid cargo through the translation of exogenously acquired $A B C B 1$ transcripts from VLB ${ }_{100} M V s$ in recipient CEM cells. We first confirm the integrity of intravesicular content in MVs using Calcein-AM and AO. After treatment of shaved MVs with calcein-AM, we detect an increase in fluorescent calcein accumulation $1.36 \pm 0.07$ fold, $(P<0.05)$ (Figure 2). This increase may be attributed to the increased permeability as a result of surface shaving. However, our observation of an increase, rather than a decrease of calcein accumulation, is indicative that MV contents remains trapped in the intravesicular space as calcein fluorescnce is dependent on the presence of cleavage of calcein AM by intravesicular esterases (Figure 2)(4, 11). We further confirm the integrity of the nucleic acid content within MVs using AO staining and observe no significant changes in fluorescence intensity in response to proteinase $\mathrm{K}$ treatment once again consistent with maintenance of integrity of MV content following shaving (Figure 3). 
In determining the optimal concentration of proteinase $\mathrm{K}$ for surface peptide shaving, we perform a Western blot analysis on MVs (Figure 4). We determined that a minimum of $50 \mathrm{ng} / \mathrm{mL}$ was required to completely remove detection of full length $170 \mathrm{kDa}$ P-gp by Western blot by cleave of its extracellular domains. Interestingly, we also observed a decrease in the $42 \mathrm{kDa} \beta$-actin detection. This data certainly may support penetration of the proteinase $\mathrm{K}$ within the intravesicular space, however it is also consistent with our previous finding, where we detected two distinct vesicle orientation with respect to proteins present on shed MVs (11). The inside-out vesicle orientation may also explain the exposure of otherwise internalised $\beta$-actin to proteinase $K$ shaving. In addition, despite the addition of serine protease inhibitors (included with protease inhibitor cocktail) and multiple cold washes, there may exist some residual proteinase $\mathrm{K}$ activity which may subsequently cause further degradation of $\beta$-actin. Once again, regardless of the possibility of proteinase $\mathrm{K}$ activity, we confirm the integrity of MVs and packaged RNA cargo by calceinAM and acridine orange staining (Figure 3).

For complete surface protein digestion, other studies have performed proteinase $\mathrm{K}$ shaving experiments with longer time frames ( $30 \mathrm{~min}-3 \mathrm{~h}$ ) and significantly increased concentrations of enzyme ( $\mu$ g amounts) (22-24). It may be possible that due to our low proteinase $\mathrm{K}$ concentrations $(50 \mathrm{ng} / \mathrm{uL}$ ) and incubation period ( $5 \mathrm{~min})$, that other membrane protein may remain intact. To adapt this method for detection of other unique proteins, this amount of proteinase $\mathrm{K}$ treatment may require additional proteinase $\mathrm{K}$ treatment optimization.

We have also previously reported that MVs isolated from $\mathrm{VLB}_{100} \mathrm{MVs}$ contain on average $2.2 \mathrm{ng}$ of total RNA for every $1 \times 10^{5} \mathrm{MVs}$ (11). On this basis, we do not expect to 
observe a large amount of translated protein relative to parental cells. Our results are consistent with this as we detect a modest $170 \mathrm{kDa}$ P-gp band in cells after co-culture with shaven MVs with Western blot analysis (Figure 5, Lane 3 and 4). This is the first demonstration of nucleic acid functionality using a human homotypic cell system. Our findings also demonstrate for the first time that MV nucleic acids are functional. In the context of cancer MDR, these nucleic acids translate into functional P-gp in recipient cancer cells and hence confer a functional drug efflux capacity (Figure 6). We also previously established that co-culture with CEM-MPs for more than $15 \mathrm{~h}$ did not induce expression of P-gp (4). Hence MP's or MP proteins do not indirectly induce transcription / translation of Pgp.

We also establish that drug efflux capacity is not evident at 4 hours MV co-culture as we observed following a simple cell to cell transfer of functional proteins (3). Rather, functionality as presented in the data here required a longer period consistent with the additional time required for mRNA translation. This data again confirms that endogenous Pgp is no longer functional, nor detectable, after proteinase K shaving (Figure 4, 6). However, after 24 hour of MV co-culture we observe a decrease in calcein accumulation in recipient cells, indicative of the acquisition of a functional drug efflux capacity following nucleic acid translation. This accumulation deficit was reversible with the addition of Cyclosporin A, consistent with the inhibition of newly translated functional P-gp (Figure 6). Although our experiments have focused on P-gp/ABCB1 transmembrane protein expression, this methodology may be adapted for the study of various membrane spanning proteins and their transcripts. This method has potential to be expanded for provide further possibilities in this regard. 


\section{Conclusions}

These results expand on our previous findings where we observed a "re-templating" of the recipient cell transcriptional landscape (4). We demonstrate the capacity of MV's to alter the recipient cell P-gp production and subsequently alter cellular phenotypes through the intercellular transfer of functional nucleic acids.

Our method allows for the observation of translated membrane proteins in a physiologically relevant host cell and eliminates the use of interspecies models and reporter markers. This provides a physiologically relevant analysis of membrane protein expression from MV cargo.

\section{Funding}

This work was supported by a grant from the National Health and Medical Research Council, Australia to M. Bebawy [APP1007613].

\section{Author Contributions Statement}

J.F.L and D.P performed experiments and wrote the manuscript. M.B. and M.P devised experiments and provided technical expertise. All authors have reviewed the manuscript.

\section{Declarations}

Competing financial Interests:

The author(s) declare no competing financial interests. 


\section{References}

(1) Jaiswal, R., Gong, J., Sambasivam, S., Combes, V., Mathys, J.-M., Davey, R., Grau, G.E.R., and Bebawy, M. (2012) Microparticle-associated nucleic acids mediate trait dominance in cancer. FASEB Journal. 26, 420-429

(2) Pokharel, D., Padula, M.P., Lu, J.F., Tacchi, J.L., Luk, F., Djordjevic, S.P., and Bebawy, M. (2014) Proteome analysis of multidrug-resistant, breast cancer-derived microparticles. Journal of Extracellular Vesicles. 3,

(3) Bebawy, M., Combes, V., Lee, E., Jaiswal, R., Gong, J., Bonhoure, A., and Grau, G. (2009) Membrane microparticles mediate transfer of P-glycoprotein to drug sensitive cancer cells. Leukemia. 23, 1643-1649

(4) Lu, J.F., Luk, F., Gong, J., Jaiswal, R., Grau, G.E., and Bebawy, M. (2013) Microparticles mediate MRP1 intercellular transfer and the re-templating of intrinsic resistance pathways. Pharmacological Research. 76, 77-83

(5) Getts, D.R., Martin, A.J., McCarthy, D.P., Terry, R.L., Hunter, Z.N., Yap, W.T., Getts, M.T., Pleiss, M., Luo, X., and King, N.J. (2012) Microparticles bearing encephalitogenic peptides induce T-cell tolerance and ameliorate experimental autoimmune encephalomyelitis. Nature biotechnology. 30, 1217-1224

(6) Jaiswal, R., Luk, F., Gong, J., Mathys, J.-M., Grau, G., and Bebawy, M. (2012) Microparticle conferred microRNA profiles-implications in the transfer and dominance of cancer traits. Molecular Cancer. 11, 37

(7) Skog, J., Würdinger, T., van Rijn, S., Meijer, D.H., Gainche, L., Curry, W.T., Carter, B.S., Krichevsky, A.M., and Breakefield, X.O. (2008) Glioblastoma microvesicles transport RNA and proteins that promote tumour growth and provide diagnostic biomarkers. Nature cell biology. 10, 1470-1476

(8) Valadi, H., Ekström, K., Bossios, A., Sjöstrand, M., Lee, J.J., and Lötvall, J.O. (2007) Exosomemediated transfer of mRNAs and microRNAs is a novel mechanism of genetic exchange between cells. Nature cell biology. 9, 654-659

(9) Bebawy, M., Morris, M., and Roufogalis, B. (2001) Selective modulation of P-glycoproteinmediated drug resistance. British Journal of Cancer. 85, 1998-2003

(10) Bebawy, M., Morris, M.B., and Roufogalis, B.D. (1999) A continuous fluorescence assay for the study of P-glycoprotein-mediated drug efflux using inside-out membrane vesicles. Analytical Biochemistry. 268, 270-277

(11) Gong, J., Luk, F., Jaiswal, R., George, A.M., Grau, G.E.R., and Bebawy, M. (2013) Microparticle drug sequestration provides a parallel pathway in the acquisition of cancer drug resistance. European journal of pharmacology. 721, 116-125

(12) Jaiswal, R., Luk, F., Dalla, P.V., Grau, G.E., and Bebawy, M. (2013) Breast cancer-derived microparticles display tissue selectivity in the transfer of resistance proteins to cells. PloS one. 8, e61515

(13) Noack, A., Noack, S., Hoffmann, A., Maalouf, K., Buettner, M., Couraud, P.-O., Romero, I.A., Weksler, B., Alms, D., and Römermann, K. (2014) Drug-induced trafficking of p-glycoprotein in human brain capillary endothelial cells as demonstrated by exposure to mitomycin C. PloS one. 9, e88154

(14) Keller, S., Konig, A., Marme, F., Runz, S., Wolterink, S., Koensgen, D., Mustea, A., Sehouli, J., and Altevogt, P. (2009) Systemic presence and tumor-growth promoting effect of ovarian carcinoma released exosomes. Cancer Letters. 278, 73 - 81 
(15) Segura, E., Guérin, C., Hogg, N., Amigorena, S., and Théry, C. (2007) CD8+ dendritic cells use LFA-1 to capture MHC-peptide complexes from exosomes in vivo. The Journal of Immunology. 179, 1489-1496

(16) Zech, D., Rana, S., Buchler, M., and Zoller, M. (2012) Tumor-exosomes and leukocyte activation: an ambivalent crosstalk. Cell Communication and Signaling. 10, 37

(17) Nolte, E.N., Buschow, S.I., Anderton, S.M., Stoorvogel, W., and Wauben, M.H. (2009) Activated T cells recruit exosomes secreted by dendritic cells via LFA-1. Blood. 113, 19771981

(18) Zhou, J., Liu, M., Aneja, R., Chandra, R., Lage, H., and Joshi, H.C. (2006) Reversal of Pglycoprotein-Mediated Multidrug Resistance in Cancer Cells by the c-Jun NH2-Terminal Kinase. Cancer Research. 66, 445-452

(19) Legrand, O., Simonin, G., Perrot, J.-Y., Zittoun, R., and Marie, J.-P. (1998) Pgp and MRP activities using calcein-AM are prognostic factors in adult acute myeloid leukemia patients. Blood. 91, 4480-4488

(20) Walter, P., and Blobel, G. (1983) [6] Preparation of microsomal membranes for cotranslational protein translocation. Methods in enzymology. 96, 84-93

(21) White, M.Y., Brown, D.A., Sheng, S., Cole, R.N., O'Rourke, B., and Van Eyk, J.E. (2011) Parallel proteomics to improve coverage and confidence in the partially annotated Oryctolagus cuniculus mitochondrial proteome. Molecular and Cellular Proteomics. 10, M110 004291

(22) Aliotta, J.M., Sanchez-Guijo, F.M., Dooner, G.J., Johnson, K.W., Dooner, M.S., Greer, K.A., Greer, D., Pimentel, J., Kolankiewicz, L.M., and Puente, N. (2007) Alteration of Marrow Cell Gene Expression, Protein Production, and Engraftment into Lung by Lung-Derived Microvesicles: A Novel Mechanism for Phenotype Modulation. Stem cells. 25, 2245-2256 Kadiu, I., Narayanasamy, P., Dash, P.K., Zhang, W., and Gendelman, H.E. (2012) Biochemical and biologic characterization of exosomes and microvesicles as facilitators of HIV-1 infection in macrophages. The Journal of Immunology. 189, 744-754

Escrevente, C., Keller, S., Altevogt, P., and Costa, J. (2011) Interaction and uptake of exosomes by ovarian cancer cells. BMC cancer. 11, 108 


\section{FIGURE LEGENDS}

Figure 1. MV's package functional $A B C B 1$ transcript. Total RNA purified from $V_{L B}{ }_{100} M V s$ were translated to protein using the rabbit reticulocyte in vitro translation kit (Promega, NSW, Australia). Detection of newly synthesized P-gp was by Western blot analysis using the anti-P-gp antibody (C219, Amersham Bioscience, NJ, USA). Novex ${ }^{\circledR}$ Sharp Pre-Stained standard (LC5800, Life technologies, Australia) was used as a molecular weight marker. A $170 \mathrm{kDa}$ was detected with addition of total VLB $100 \mathrm{MV}$ RNA. Data is representative of 2 independent experiments.

Figure 2. MV integrity is maintained following proteinase $\mathrm{K}$ shaving. (a) MV's isolated from $\mathrm{VLB}_{100}$ were analysed by FCM. Latex beads (BD Bioscience) of 0.3 and $1.1 \mu \mathrm{M}$ were used to define the upper and lower limit of the forward and side scatter (data not shown). (b) Shaved and unshaved MVs were stained for phosphatidylserine exposure using Annexin V450; unstained background control. (c) Intravesicular calcein accumulation in shaved and unshaved VLB ${ }_{100}$ MVs with increasing proteinase $\mathrm{K}$ concentration. (d) Acridine orange stained shaved, unshaved VLB 100 MVs and unstained background control. Data is representative of three independent experiments

Figure 3. RNA content and MV binding retained following $M V$ shaving. VLB ${ }_{100} M V s$ are shaved using $50 \mathrm{ng} / \mathrm{mL}$ of proteinase $\mathrm{K}$ for 5 minutes at $37^{\circ} \mathrm{C}$. Shaved MVs and non-shaved MVs were stained with (a) acridine orange and (b) PKH26 prior to co-culture with CEM cells (4 hours). Recipient cells are analysed by FCM to determine extent of RNA transfer and MV binding from shaven relative to non-shaved MVs. Unlabelled CEM cells. Data is representative of 3 independent experiments.

Figure 4. Surface shaving of P-gp by proteinase K. (a) Graphical representation of MV surface shaving methodology. Exposed surface peptides on P-gp are cleaved following treatment with proteinase $K$, reducing the overall molecular weight of membrane bound MV proteins. (b) Western blot detection of P-gp after surface shaving with increasing amounts of proteinase K. P-gp was detected using the anti-P-gp antibody, clone F4, SigmaAldrich, NSW, Australia). $\beta$-actin was detected on proteinase-K treatments below $100 \mathrm{ng} / \mathrm{mL}$ (clone AC-74, Sigma-Aldrich). Novex ${ }^{\circledR}$ Sharp Pre-Stained standard (LC5800, Life technologies, Australia) was used as a molecular weight marker. Data is representative of 2-3 independent experiments. 
Figure 5. Translation of MV contained $A B C B 1$ transcript in recipient cells. (a) Graphical representation of translation of transferred MV RNA in recipient cells. Surface shaved $\mathrm{VLB}_{100} \mathrm{MVs}$ were co-cultured with drug sensitive CEM cells to allow transfer of MV mRNA cargo. Transferred $A B C B 1$ transcript translates to a $170 \mathrm{kDa}$ surface protein in recipient cells. (b) Translated P-gp/ABCB1 were detected using Western blot analysis. P-gp was detected in CEM cells after $19 \mathrm{~h}$ of co-culture with shaved VLB ${ }_{100}$ MVs using anti-P-gp mAb (Clone F4, Sigma-Aldrich, NSW, Australia). All MV's were shaven with $50 \mathrm{ng} / \mathrm{uL}$ of proteinase $\mathrm{K}$ for 5 mins at $37^{\circ} \mathrm{C}$ with gentle shaking. Novex ${ }^{\circledR}$ Sharp Pre-Stained standard (LC5800, Life technologies, Australia) was used as a molecular weight marker. Data is representative of a typical experiment $(n=2-3)$.

Figure 6. Newly translated P-gp is functional. Calcein accumulation in CEM cells after (a) $4 \mathrm{~h}$ or (b) $24 \mathrm{~h}$ co-culture with shaved VLB ${ }_{100} M V$ s. Data represents the fold decrease in calcein accumulation relative to CEM cells. A decrease in calcein accumulation in CEM cells was observed after a $24 \mathrm{~h}$ co-culture with shaved $\mathrm{VLB}_{100} \mathrm{MVs}$. The accumulation deficit was reversed following CSA exposure. No significant shift in fluorescence was detected in CEM cells co-cultured with $\mathrm{VLB}_{100} \mathrm{MVs}$ after $4 \mathrm{~h}$. Data represents the mean \pm S.E.M of at least 3 independent experiments. $* P<0.05$ 


\section{Figure 1}

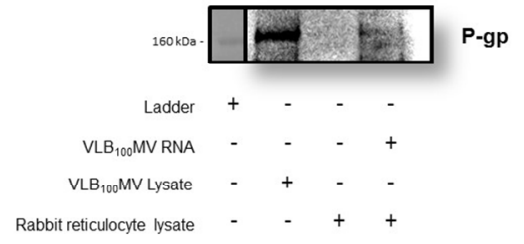

Figure 1. MV's package functional ABCB1 transcript. Total RNA purified from VLB100MVs were translated to protein using the rabbit reticulocyte in vitro translation kit (Promega, NSW, Australia). Detection of newly synthesized P-gp was by Western blot analysis using the anti-P-gp antibody (C219, Amersham Bioscience,

NJ, USA). Novex $®$ Sharp Pre-Stained standard (LC5800, Life technologies, Australia) was used as a molecular weight marker. A $170 \mathrm{kDa}$ was detected with addition of total VLB100MV RNA. Data is representative of 2 independent experiments. $338 \times 190 \mathrm{~mm}(96 \times 96 \mathrm{DPI})$ 


\section{Figure 2}

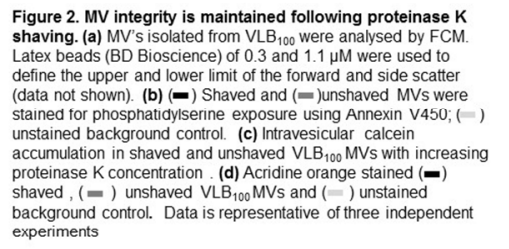

shaving. (a) MV's isolated from VLB 100 were analysed by $F C M$.
Latex beads (BD Bioscience) of 0.3 and $1.1 \mu \mathrm{M}$ were used to define the upper and lower limit of the forward and side scatter stained tor phosphatidyiserine exposure using Annexin V4bU; (unstained background control. (c) Intravesicular calcein proteinase K concentration (d) Acridine orange stained (experiments
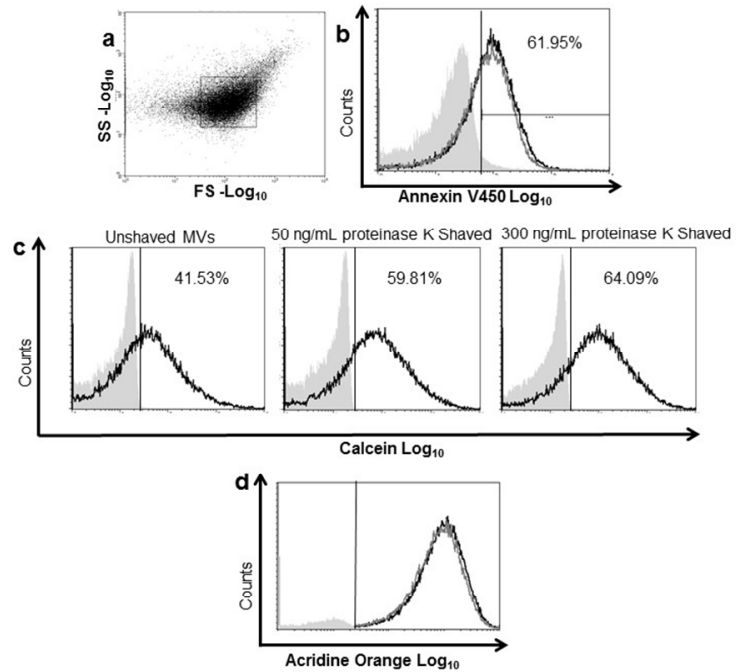

Figure 2. MV integrity is maintained following proteinase $\mathrm{K}$ shaving. (a) MV's isolated from VLB100 were analysed by FCM. Latex beads (BD Bioscience) of 0.3 and $1.1 \mu \mathrm{M}$ were used to define the upper and lower limit of the forward and side scatter (data not shown). (b) Shaved and unshaved MVs were stained for phosphatidylserine exposure using Annexin V450; unstained background control. (c) Intravesicular calcein accumulation in shaved and unshaved VLB100 MVs with increasing proteinase K concentration. (d) Acridine orange stained shaved, unshaved VLB100 MVs and unstained background control. Data is representative of three independent experiments

$338 \times 190 \mathrm{~mm}(96 \times 96$ DPI) 


\section{Figure 3}
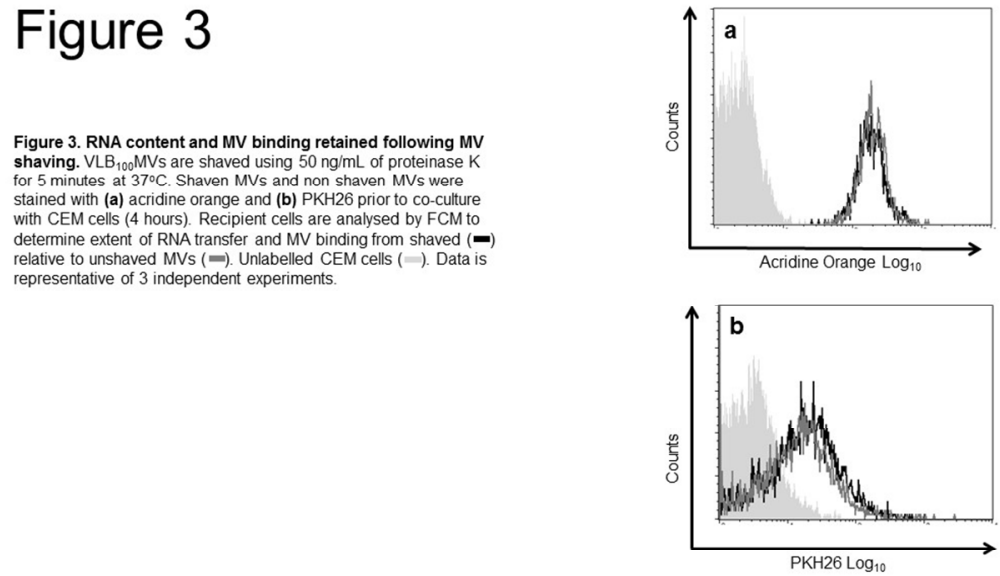

Figure 3. RNA content and MV binding retained following MV shaving. VLB100MVs are shaved using 50 $\mathrm{ng} / \mathrm{mL}$ of proteinase $\mathrm{K}$ for 5 minutes at $370 \mathrm{C}$. Shaved MVs and non-shaved MVs were stained with (a) acridine orange and (b) PKH26 prior to co-culture with CEM cells (4 hours). Recipient cells are analysed by FCM to determine extent of RNA transfer and MV binding from shaven relative to non-shaved MVs. Unlabelled CEM cells. Data is representative of 3 independent experiments. $338 \times 190 \mathrm{~mm}(96 \times 96 \mathrm{DPI})$ 


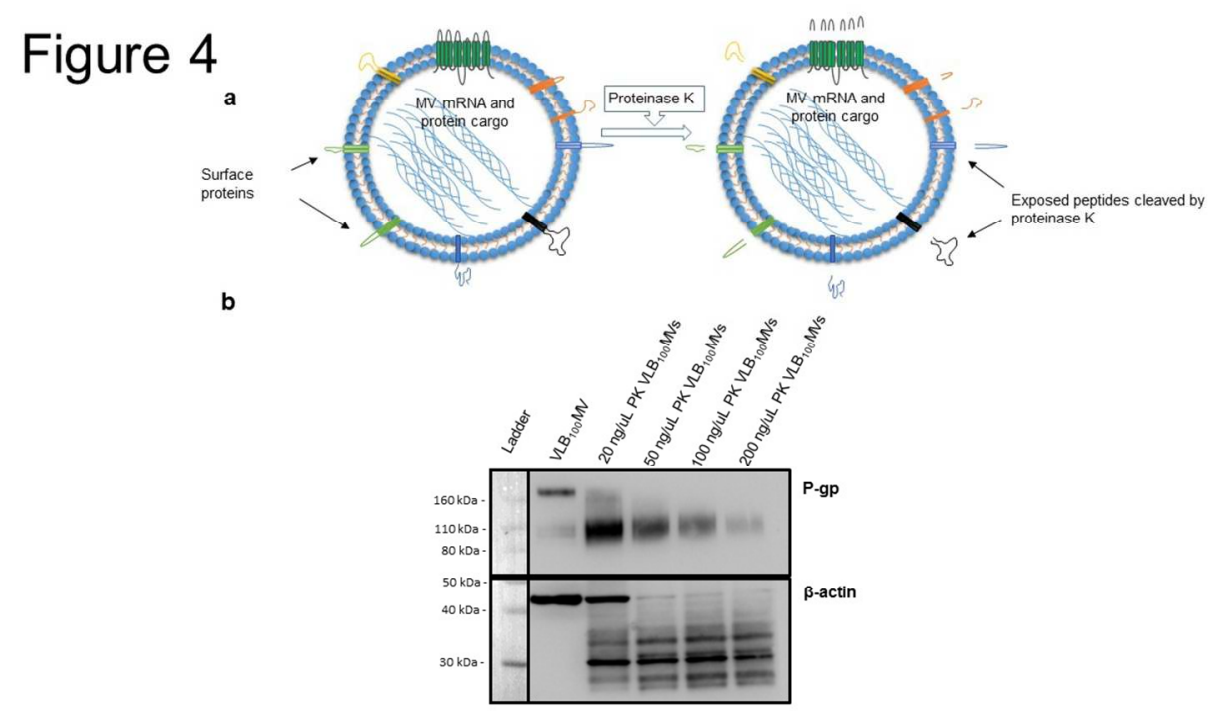

Figure 4. Surface shaving of P-gp by proteinase K. (a) Graphical representation of MV surface shaving methodology. Exposed surface peptides on $\mathrm{P}$-gp are cleaved following treatment with proteinase $\mathrm{K}$, reducing the overall molecular weight of membrane bound MV proteins. (b) Western blot detection of P-gp after surface shaving with increasing amounts of proteinase K. P-gp was detected using the anti-P-gp antibody, clone F4, Sigma-Aldrich, NSW, Australia). $\beta$-actin was detected on proteinase-K treatments below 100 $\mathrm{ng} / \mathrm{mL}$ (clone AC-74, Sigma-Aldrich). Novex $®$ Sharp Pre-Stained standard (LC5800, Life technologies, Australia) was used as a molecular weight marker. Data is representative of 2-3 independent experiments. $338 \times 190 \mathrm{~mm}(96 \times 96 \mathrm{DPI})$ 


\section{Figure 5}

a

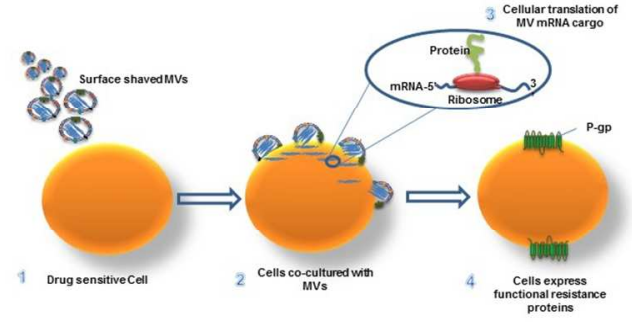

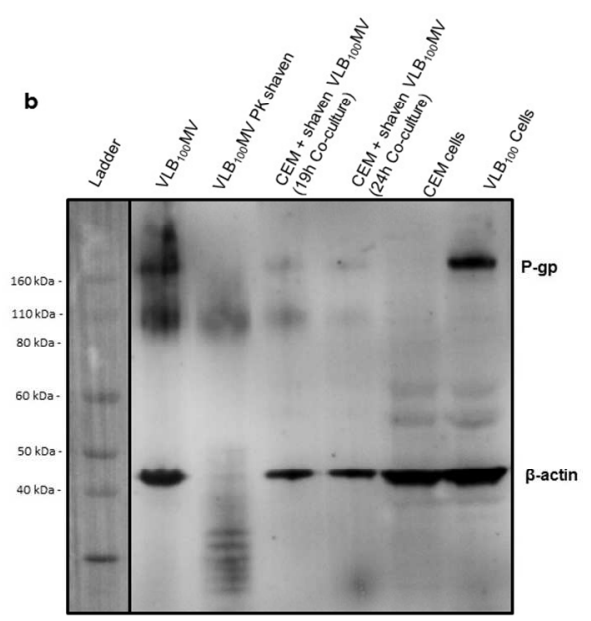

Figure 5. Translation of MV contained ABCB1 transcript into recipient cells. (a) Graphical representation of translation of transferred MV RNA in recipient cells. Surface shaved VLB100MVs were co-cultured with drug sensitive CEM cells to allow transfer of MV mRNA cargo. Transferred ABCB1 transcript translates to a 170

kDa surface protein in recipient cells. (b) Translated P-gp/ABCB1 were detected using Western blot analysis. P-gp was detected in CEM cells after $19 \mathrm{~h}$ of co-culture with shaved VLB100MVs using anti-Pgp mAb (Clone F4, Sigma-Aldrich, NSW, Australia). All MV's were shaven with $50 \mathrm{ng} / \mathrm{uL}$ of proteinase K for 5 mins at 370C with gentle shaking. Novex $®$ Sharp Pre-Stained standard (LC5800, Life technologies, Australia) was used as a molecular weight marker. Data is representative of a typical experiment $(n=2-3)$. $338 \times 190 \mathrm{~mm}(96 \times 96 \mathrm{DPI})$ 


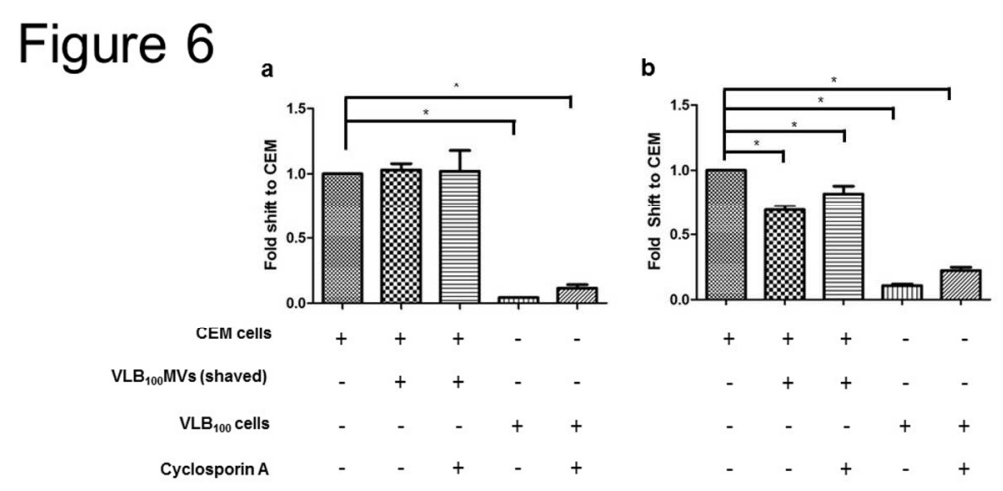

Figure 6. Newly translated P-gp is functional. Calcein accumulation in CEM cells after (a) $4 \mathrm{~h}$ or (b) $24 \mathrm{~h}$ coculture with shaved VLB100MVs. Data represents the fold decrease in calcein accumulation relative to CEM cells. A decrease in calcein accumulation in CEM cells was observed after a $24 \mathrm{~h}$ co-culture with shaved VLB100MVs. The accumulation deficit was reversed following CsA exposure. No significant shift in fluorescence was detected in CEM cells co-cultured with VLB100MVs after $4 \mathrm{~h}$. Data represents the mean \pm S.E.M of at least 3 independent experiments. $* P<0.05$ $338 \times 190 \mathrm{~mm}(96 \times 96 \mathrm{DPI})$ 
Table 1. List of homo sapien proteins translated from $\mathrm{VLB}_{100} \mathrm{MV}$ RNA using rabbit lysate translation assay as analysed by LC/MS/MS

\begin{tabular}{|c|c|c|c|c|}
\hline \multirow[t]{2}{*}{ No. } & \multirow[t]{2}{*}{$\begin{array}{l}\text { Name of } \\
\text { protein }\end{array}$} & \multicolumn{2}{|c|}{$\begin{array}{l}\text { No of unique } \\
\text { peptides detected } \\
\text { in } 3 \text { independent } \\
\text { replicates }\end{array}$} & Function \\
\hline & & Translation & Background & \\
\hline 1 & $\begin{array}{l}\text { P-glycoprotein } \\
\text { (P-gp) }\end{array}$ & $8-5-5$ & $0-0-0$ & $\begin{array}{l}\text { ATP-binding cassette transporter protein. } \\
\text { Overexpression in cancer cells is strongly } \\
\text { associated with } \operatorname{MDR}(3,25) \text {. }\end{array}$ \\
\hline 2 & $\begin{array}{l}\text { 60S ribosomal } \\
\text { protein } L 26 \\
\text { (RPL26) }\end{array}$ & $2-2-0$ & $0-0-0$ & $\begin{array}{l}\text { Binding of RPL } 26 \text { to the } 5^{\prime} \text { UTR of p53 gene, } \\
\text { modulate p53 protein levels and affect p53 } \\
\text { induction after DNA damage. P53 gene is } \\
\text { commonly mutated in human cancer and lead to } \\
\text { the cancer-predisposing Li-Fraumeni syndrome } \\
(26) \text {. } \\
\text { Ribosomal proteins are reported to be increased } \\
\text { in human cancer and in maintaining cancer } \\
\text { phenotype }(27,28) \text {. }\end{array}$ \\
\hline 3 & $\begin{array}{l}\text { Isoform } 2 \text { of } \\
4 F 2 \text { cell- } \\
\text { surface } \\
\text { antigen heavy } \\
\text { chain (SLC3A2) }\end{array}$ & $3-1-3$ & $0-0-0$ & $\begin{array}{l}\text { SLC3A2 is the protein that is encoded by SLC3A2 } \\
\text { gene, which binds to a highly conserved C- } \\
\text { terminal domain of integrin } \beta 1 A \text { and } \beta 3 \\
\text { cytoplasmic subunits, thereby affecting the } \\
\text { integrin signalling cascade (29). } \\
\text { These proteins influences malignant tumour cell } \\
\text { behaviour and overexpressed in variety of } \\
\text { cancers by contributing to tumour growth (30). }\end{array}$ \\
\hline 4 & $\begin{array}{l}\text { Proteasome } \\
\text { subunit beta } \\
\text { type-6 } \\
\text { (PSMB6) }\end{array}$ & $2-2-1$ & $0-0-0$ & $\begin{array}{l}\text { PSMB6 is a member of } 20 S \text { proteasomal subunit } \\
\text { family, which forms the proteolytic core of } 26 S \\
\text { proteasome. Enhanced proteasomal activity has } \\
\text { been demonstrated as a mediator of resistance } \\
\text { to chemotherapy (31). } \\
\text { Over expression of the PSMB1 proteasomal }\end{array}$ \\
\hline
\end{tabular}


subunit is associated with resistance to cisplatin in cancer cell lines (32) and associated with anthracycline-resistance in breast cancer (33).

\begin{tabular}{|c|c|c|c|c|}
\hline 5 & $\begin{array}{l}\text { Sodium/Potass } \\
\text { ium- } \\
\text { transporting } \\
\text { ATPase } \\
\text { subunit alpha- } \\
4 \text { (ATP1A4) }\end{array}$ & $2-0-2$ & $0-0-0$ & $\begin{array}{l}\text { ATP1A4 was reported to overexpressed in } \\
\text { pancreas tumour compared with normal cells } \\
\text { (34). }\end{array}$ \\
\hline
\end{tabular}

